\title{
Avaliação de viabilidade técnica da produção de madeira serrada de árvores de Eucalyptus benthamii de rotação reduzida
}

\author{
Bruna Verediana Müller ${ }^{1}$, Márcio Pereira da Rocha ${ }^{2}$, Alexsandro Bayestorff da Cunha ${ }^{3}$, Ricardo \\ Jorge Klitzke ${ }^{2}$, José Reinaldo Moreira da Silva ${ }^{4}$

\footnotetext{
${ }^{1}$ Instituto Federal de Educação, Ciência e Tecnologia Catarinense, Rio do Sul- SC, Brasil.

${ }^{2}$ Departamento de Engenharia e Tecnologia Florestal, Universidade Federal do Paraná, Curitiba - PR, Brasil.

${ }^{3}$ Departamento de Engenharia Florestal, Universidade do Estado de Santa Catarina, Lages - SC, Brasil.

${ }^{4}$ Departamento de Ciências Florestal, Universidade Federal de Lavras, Lavras - MG, Brasil
}

\begin{abstract}
RESUMO O Eucalyptus benthamii está sendo plantado em Santa Catarina via incentivos, no entanto, o uso adequado da espécie necessita estudos específicos. O objetivo desta pesquisa foi avaliar o efeito do diâmetro de toras e do modelo de desdobro na produção de madeira serrada de Eucalyptus benthamii provenientes de árvores com seis anos. Foram selecionadas 42 toras, de duas classes diamétricas (20-24,9 e 25-29,9 cm), submetidas a três modelos de desdobro (Modelo 1: em bloco, Modelo 2: em bloco com uma face curva e Modelo 3: radial) que compreenderam seis tratamentos. Para cada tratamento, foi determinado o volume de toras pelo método de Newton. Ao final dos processos de desdobro e secagem, as tábuas produzidas tiveram suas dimensões e rachaduras mensuradas para a determinação do rendimento em madeira serrada. Os resultados obtidos demonstraram que o rendimento em madeira serrada foi mais influenciado pelo modelo de desdobro, do que pela classe diamétrica. Para o sistema de desdobro após a secagem, o modelo 2 foi superior aos demais na classe inferior, e os modelos 2 e 3 foram equivalentes na inferior. Todos os rendimentos obtidos foram baixos, o que demonstra que o desdobro do Eucalyptus benthamii com idade reduzida não é indicado.
\end{abstract}

Palavras-chave: eucalipto; rendimento em madeira serrada; modelo de desdobro.

\section{Technical viability evaluation of the lumber production Eucalyptus benthamii trees of reduced rotation}

\begin{abstract}
Eucalyptus benthamii is being planted in Santa Catarina via incentives, however, the proper use of the species requires specific studies. The objective of this study was to evaluate the effect of log diameter and the sawing patterns on the production of Eucalyptus benthamii lumber from six years old trees. Logs from two diameter classes (20-24,9 and 25-29,9 cm) were selected and subject to the three sawing patterns (Model 1: cant-sawing, Model 2: cant-sawing with one curved face and Model 3: quarter-sawing) that comprised six treatments. For each treatment, the logs volume was determined by the Newton's method. At the end of the sawing and drying processes, the dimensions and the splits of the resulting tables were measured for determining the lumber yeld. The results obtained showed that the lumber yield was more influenced by the sawing patterns than by the diameter classes. For the sawing pattern after drying, Model 2 was superior to the others in the lower class, and Models 2 and 3 were equivalent in the lower one. All yields obtained were low, demonstrating that Eucalyptus benthamii sawing, with logs of reduced age, is not indicated.
\end{abstract}

Keywords: eucalypt; lumber yield; sawing pattern.

\section{Introdução}

O Eucalyptus benthamii Maiden et Cambage é uma espécie originária da Austrália e foi introduzido no Brasil em 1988 pela Embrapa Florestas (GRAÇA et al., 1999). Por apresentar boa resistência à ocorrência de geadas severas, rápido crescimento e excelente forma de fuste, esta espécie tem despertado o interesse de instituições de pesquisa e de empreendedores do setor florestal na região sul do país. No entanto, apesar de 
todo o interesse pelo Eucalyptus benthamii, poucos trabalhos foram realizados sobre a sua utilização como fonte de matéria-prima para os diferentes segmentos da indústria madeireira, principalmente, quando considerado o seu emprego na produção de serrados.

Normalmente, a produção de madeira serrada de eucalipto requer alguns cuidados, sobretudo em função da significativa manifestação das tensões de crescimento e da elevada instabilidade dimensional, principalmente quando se trata de madeira juvenil (BIECHELE et al., 2009; KOJIMA et al., 2009). Na maioria das vezes, essas características são as principais responsáveis pelos baixos rendimentos no processamento da madeira, uma vez que podem originar rachaduras e empenamentos, antes e durante o desdobro que, em algumas situações, são acentuados durante a secagem (SILVA et al., 2017; ELEOTÉRIO et al., 2014; SOUZA et al., 2012; KOJIMA et al., 2012).

Diversas estratégias têm sido empregadas para desdobrar toras do gênero Eucalyptus (WASHUSEN et al., 2009; JONES et al., 2010). O sistema de desdobro tangencial de eucalipto proporciona boa produtividade e boa precisão em relação às dimensões de corte das tábuas, enquanto o radial apresenta menor eficiência operacional e rendimento em madeira serrada, porém produz peças mais estáveis dimensionalmente e menos propensas a formação de defeitos (ROCHA; TOMASELLI, 2001; ROCHA; TOMASELLI, 2002). Juizo et al. (2014), ao avaliarem os desdobros radial e tangencial no processamento de toras de Eucalyptus cloeziana e Eucalyptus saligna de duas classes diamétricas concluíram que, independentemente da espécie ou diâmetro, os maiores rendimentos foram obtidos no desdobro tangencial.

De acordo com Wade et al. (1992), outro fator a influenciar no rendimento em madeira serrada é o diâmetro das toras. De acordo com os mesmos autores, normalmente as toras de maior diâmetro resultam em maiores rendimentos. Já Del
Menezzi e Nahuz (1998), por exemplo, ao estudarem o desdobro de toras de Eucalyptus grandis, observaram redução do rendimento médio com a elevação do diâmetro médio das toras, e sugeriram que além do diâmetro, outros fatores como a qualidade da tora, a técnica de desdobro empregada e os equipamentos utilizados nas operações de corte também podem interferir no rendimento em madeira serrada.

Assim, a definição do sistema de desdobro mais apropriado para o processamento do Eucalyptus benthamii, bem como o conhecimento das implicações do uso de toras de diferentes classes diamétricas, são imprescindíveis para que a espécie seja utilizada de forma mais racional pela indústria de madeira serrada. Deste modo, o objetivo deste estudo foi avaliar o efeito do diâmetro de toras e do modelo de desdobro na produção de madeira serrada de Eucalyptus benthamii.

\section{Material e Métodos}

\section{Obtenção do material}

As toras foram obtidas em um plantio comercial de $E \mathcal{~ - ~}$ calyptus benthamii com seis anos de idade e espaçamento inicial de 2,5 x 2,0 m, situado no distrito de São Jorge, município de Cerro Negro (27 $47^{\prime} 43^{\prime \prime}$ S e $50^{\circ} 52^{\prime} 33^{\prime \prime}$ W), Estado de Santa Catarina.

Foram avaliados seis tratamentos, resultantes da combinação de duas classes diamétricas de toras (classe 1: 20,0 $24,9 \mathrm{~cm}$; classe 2: 25,0 - 29,9 cm) e três modelos de desdobro (Modelo 1: em bloco, Modelo 2: em bloco com uma face curva e Modelo 3: radial).

Assim, para a obtenção das toras, as árvores foram selecionadas com base no diâmetro à altura do peito $\left(D_{1,30 m}\right)$ (para atender às duas classes diamétricas citadas anteriormente), as quais foram derrubadas e seccionadas em toras com comprimento médio de 1,95 m, de forma semi-mecanizada. Destas, selecionaram-se somente as primeiras toras (sete por tratamento), que totalizaram 42 toras avaliadas. 
As toras foram cubadas pelo método de Newton (SOARES et al., 2006) e desdobradas em até 72 horas após a colheita, conforme recomendação de Rocha; Trugilho (2006), e produziram peças de $24 \mathrm{~mm}$ de espessura nominal.

\section{Modelos de desdobro}

O modelo 1 é um sistema de desdobro para blocos, no qual as toras passaram duas vezes em uma serra fita tandem para a formação do bloco, que foi resserrado em serra de fita horizontal de múltiplos cabeçotes. As quatro costaneiras foram reaproveitadas em serra de fita horizontal com dois cabeçotes e refiladas em serra circular dupla (Figura 1).

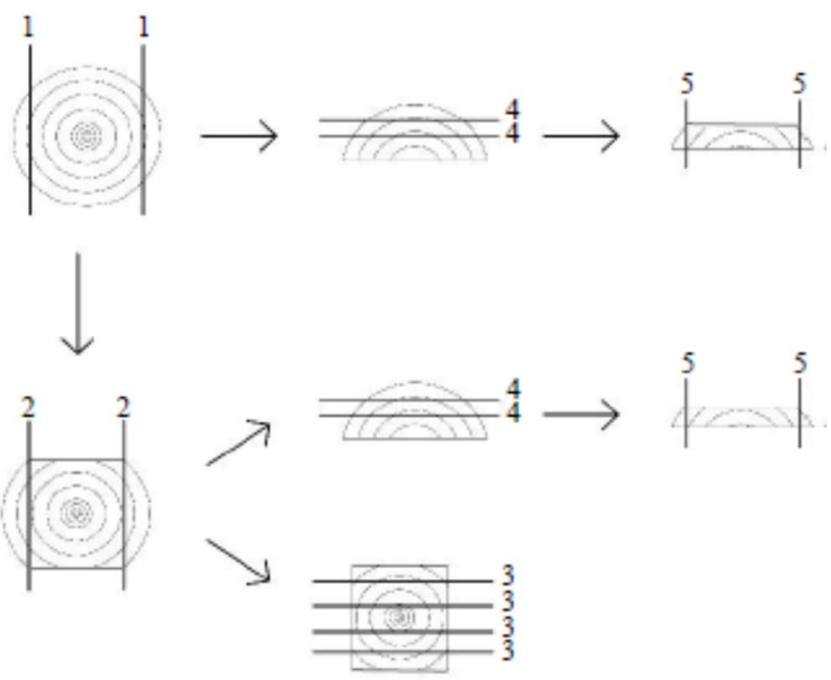

Figura 1. Descrição do processo de desdobro do modelo 1. Figure 1. Model's 1 description of the sawmilling process.

O modelo 2 também é um sistema de desdobro para blocos, mas difere do anterior por proceder com uma face curva. Neste, as toras passaram primeiramente numa serra fita horizontal, onde foi realizado um corte na parte inferior das mesmas, que originou um semibloco com uma face plana e uma costaneira. O semibloco foi encaminhado para uma serra fita geminada para a retirada de duas costaneiras. Em seguida, o semibloco com uma face curva foi resserrado em serra de fita horizontal de múltiplos cabeçotes, ao passo que as quatro cos- taneiras foram refiladas em serra circular dupla e reaproveitadas em serra de fita horizontal com dois cabeçotes (Figura 2).
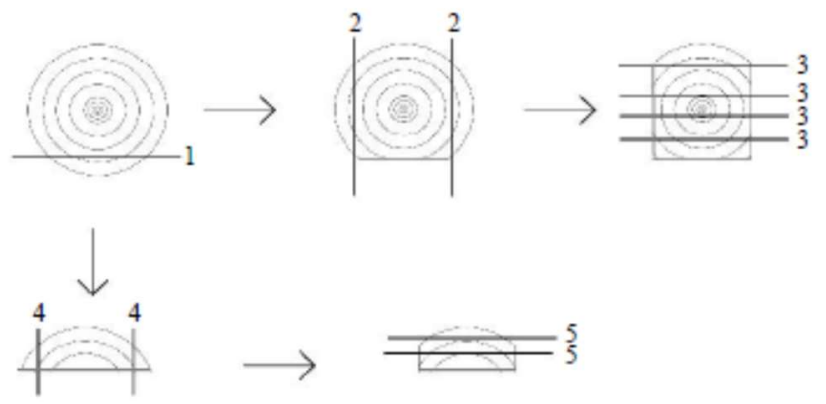

Figura 2. Descrição do processo de desdobro do modelo 2. Figure 2. Model's 2 description of the sawmilling process.

O modelo 3 é um sistema de desdobro radial, no qual as toras passaram em serra de fita tandem, onde foram realizados dois cortes perpendiculares de forma alternada: um para gerar uma costaneira (não aproveitada) e outro para dividir a tora em duas. Na sequência, as metades da tora foram processadas em serra fita simples vertical para a obtenção de tábuas, que por sua vez foram refiladas em serra circular simples (Figura 3).

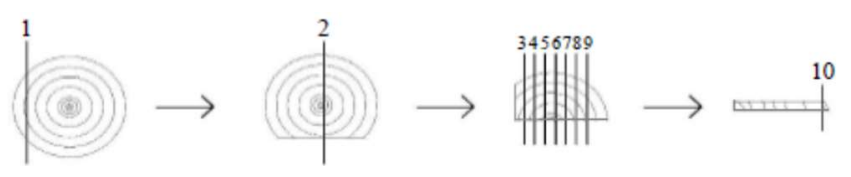

Figura 3. Descrição do processo de desdobro do modelo 3. Figure 3. Model's 3 description of the sawmilling process.

\section{Avaliação do rendimento em madeira serrada}

Após o desdobro, as tábuas tiveram suas dimensões mensuradas pelo método estereométrico, com o auxílio de um paquímetro $(0,01 \mathrm{~mm})$ para a medição da espessura e largura em três pontos de cada peça (extremidades e centro). O comprimento foi determinado por uma única medição, tomada na parte central de cada tábua. Durante esse processo, foram 
mensurados os comprimentos das maiores rachaduras presentes nas extremidades das tábuas. Tanto as medições do comprimento das tábuas, como das rachaduras foram realizadas com fita métrica $(0,1 \mathrm{~cm})$.

Em seguida, a madeira foi empilhada para secagem natural sob cobertura por um período de 90 dias. Ao término desse período, por meio do método de pesagem ou gravimétrico, foi determinado o teor de umidade final da madeira, cujo o valor obtido foi de $17,5 \%$, e repetiu-se o processo de mensuração das tábuas, o que permitiu que o rendimento em madeira serrada fosse avaliado em condição saturada após o desdobro e após secagem natural (17,5\% de umidade).

Deste modo, com base na metodologia proposta por $\mathrm{Cu}$ nha et al. (2015), para cada tratamento determinou-se o rendimento bruto e o rendimento sem as rachaduras (considerando apenas o volume de tábuas livre de rachaduras) nas condições saturada e seca a $17,5 \%$ de umidade.

\section{Análise estatística}

A análise estatística foi realizada em delineamento inteiramente casualisado, em arranjo fatorial e o nível de significância adotado para todos os testes foi de até 5\%. Analisaramse os fatores classe diamétrica (dois níveis) e modelos de desdobro (três níveis).

Para verificar o efeito dos tratamentos, foi realizada a análise de variância (ANOVA), cujos resultados foram submetidos ao teste de Tukey para comparação de médias, sempre que a hipótese da nulidade foi rejeitada $(\mathrm{P}<0,05)$. Para todos os testes foi utilizadoo software Sisvar 5.1 Build $72^{\circ}$.

\section{Resultados e Discussão}

Para a condição saturada, o efeito dos fatores modelo de desdobro e classe diamétrica, bem como a interação entre eles, foi significativo em ambos os rendimentos avaliados.
Para a condição a $17,5 \%$ de umidade o modelo de desdobro apresentou efeito significativo sobre os diferentes rendimentos considerados, mas ao se avaliar o efeito da classe diamétrica, o mesmo só foi verificado no rendimento bruto, enquanto para a interação entre os fatores, o efeito significativo só foi verificado no rendimento sem as rachaduras.

Se for considerado que as rachaduras da madeira são provocadas pelas tensões internas de crescimento (LIMA; GARCIA, 2008; ANJOS; FONTE, 2017a) e que essas tensões estão associadas ao diâmetro de toras (CARVALHO et al., 2010), o fato da classe diamétrica não ter apresentado efeito significativo sobre os rendimentos sem as rachaduras após o processo de secagem, pode estar relacionado ao processo de liberação das tensões de crescimento. De acordo com Cademartori et al. (2015), a maioria das tensões de crescimento é liberada durante o abate da árvore e no processo de desdobro da madeira, assim a formação de rachaduras na secagem é originada principalmente pelas tensões de secagem e em menor escala, pelas tensões de crescimento.

De modo geral, os resultados indicaram que, independente da condição de umidade, o fator de maior influência no rendimento em madeira serrada de Eucalyptus benthamii, foi o modelo de desdobro, o que possivelmente decorre dos equipamentos adotados e também do número de cortes realizados em cada um dos modelos.

Juizo et al. (2014), ao estudarem o rendimento de duas espécies de Eucalyptus spp. logo após o desdobro, observaram o efeito significativo do modelo de desdobro, o que corrobora com o encontrado neste estudo. No entanto, o mesmo não foi verificado quando considerada a variável classe diamétrica e a sua interação com o modelo de desdobro. Todavia, cabe ressaltar, que as classes diamétricas de toras usadas por estes autores $(30-34,5$ e $35-39,5 \mathrm{~cm})$ foram superiores as utilizadas neste estudo. 
Em relação aos resultados apresentados na Tabela 1, verificou-se que o efeito significativo da classe diamétrica somente ocorreu quando considerado o Modelo 2, exceto para o rendimento sem rachaduras na condição a $17,5 \%$ de umidade, para o qual, no geral, foi verificada a tendência de elevação dos rendimentos com o aumento do diâmetro das toras.

Deve-se salientar que no caso dos outros modelos de desdobro, nas duas condições de umidade avaliadas, essa mesma tendência em relação às classes diamétricas também foi observada para a maioria dos tratamentos. Embora não tenha sido significativa do ponto de vista estatístico, é relevante no que diz respeito aos aspectos econômicos do processo produtivo, uma vez que aumenta de forma considerável o aproveitamento da matéria prima.

Além disso, para o rendimento bruto na condição saturada, quando considerados os percentuais obtidos para cada modelo de desodobro dentro de cada classe diamétrica, verificou-se que na classe 1 a diferença entre os percentuais obtidos entre modelos de desobro para blocos (1 e 2) e modelo de desdobro radial (3) foi menor do que a diferença observada na classe 2 , indicando que no modelo de desdobro radial há necessidade de utilização de toras de maior diâmetro.

Anjos; Fonte (2017b), ao estudarem o rendimento em madeira serrada de Eucalyptus dunnii, Eucalyptus grandis e Eucalyptus saligna, obtiveram resultados similares ao do presente estudo, verificando que, independente da espécie, os maiores rendimentos foram obtidos pelas classes de maior diâmetro. Por outro lado, Cunha et al. (2015), ao realizarem um estudo semelhante, avaliando o efeito de duas classes diamétricas de Eucalyptus benthamii aos 13 anos de idade nos desdobros tangencial e radial, observaram uma tendência

Tabela 1. Rendimentos em madeira serrada de Eucalyptus benthamii em diferentes condições de umidade.

Table 1. Yelds of Eucalyptus benthamii sawnwood in different moisture conditions.

\begin{tabular}{|c|c|c|c|c|c|}
\hline \multirow{3}{*}{$\begin{array}{l}\text { Rendimento } \\
\text { considerado }\end{array}$} & \multirow{3}{*}{$\begin{array}{l}\text { Técnicas de } \\
\text { desdobro }\end{array}$} & \multicolumn{2}{|c|}{ Saturada } & \multicolumn{2}{|c|}{ Secagem natural a $17,5 \%$} \\
\hline & & $\begin{array}{c}\text { Classe } 1 \\
(20-24,9 \mathrm{~cm} \text { de } \varnothing)\end{array}$ & $\begin{array}{c}\text { Classe } 2 \\
(25-29,9 \mathrm{~cm} \text { de } \varnothing)\end{array}$ & $\begin{array}{c}\text { Classe } 1 \\
(20-24,9 \mathrm{~cm} \text { de } \varnothing)\end{array}$ & $\begin{array}{c}\text { Classe } 2 \\
(25-29,9 \mathrm{~cm} \mathrm{de} \varnothing)\end{array}$ \\
\hline & & Média & Média & Média & Média \\
\hline \multirow{3}{*}{$\begin{array}{c}\text { Bruto } \\
(\%)\end{array}$} & $\begin{array}{l}\text { Modelo } 1 \\
\text { (Bloco) }\end{array}$ & $\begin{array}{c}40,71^{\mathrm{A} \mathrm{a}} \\
(1,47)\end{array}$ & $\begin{array}{c}43,11^{\text {A a }} \\
(1,89)\end{array}$ & $\begin{array}{c}33,73^{\text {A a }} \\
(4,84)\end{array}$ & $\begin{array}{c}34,19^{\text {A a }} \\
(3,70)\end{array}$ \\
\hline & $\begin{array}{l}\text { Modelo } 2 \\
\text { (Bloco com } \\
\text { face curva) }\end{array}$ & $\begin{array}{c}37,15^{\text {В в }} \\
(2,21)\end{array}$ & $\begin{array}{c}43,44^{\mathrm{A} \mathrm{a}} \\
(1,92)\end{array}$ & $\begin{array}{c}29,70^{\text {В b }} \\
(2,80)\end{array}$ & $\begin{array}{c}32,80^{\mathrm{AB} \mathrm{a}} \\
(2,57)\end{array}$ \\
\hline & $\begin{array}{c}\text { Modelo } 3 \\
\text { (Radial) }\end{array}$ & $\begin{array}{c}35,33^{\mathrm{Ca}} \\
(2,32)\end{array}$ & $\begin{array}{c}38,13^{\text {В а }} \\
(2,18)\end{array}$ & $\begin{array}{c}29,55^{\text {В а }} \\
(2,80)\end{array}$ & $\begin{array}{c}31,53^{\text {в а }} \\
(2,62)\end{array}$ \\
\hline \multirow{3}{*}{$\begin{array}{l}\text { Sem as ra- } \\
\text { chaduras } \\
(\%)\end{array}$} & $\begin{array}{l}\text { Modelo } 1 \\
\text { (Bloco) }\end{array}$ & $\begin{array}{c}25,78^{\mathrm{B} \mathrm{a}} \\
(6,33)\end{array}$ & $\begin{array}{c}24,55^{\mathrm{Ca}} \\
(6,82)\end{array}$ & $\begin{array}{c}18,42^{\mathrm{Ca}} \\
(4,44)\end{array}$ & $\begin{array}{c}13,21^{\text {Ва }} \\
(6,20)\end{array}$ \\
\hline & $\begin{array}{l}\text { Modelo } 2 \\
\text { (Bloco com } \\
\text { face curva) }\end{array}$ & $\begin{array}{c}29,51^{\text {A a }} \\
(2,79)\end{array}$ & $\begin{array}{c}37,82^{\mathrm{A} \mathrm{b}} \\
(1,96)\end{array}$ & $\begin{array}{c}20,79^{\text {В а }} \\
(4,01)\end{array}$ & $\begin{array}{c}25,60^{\text {A a }} \\
(3,22)\end{array}$ \\
\hline & $\begin{array}{l}\text { Modelo } 3 \\
\text { (Radial) }\end{array}$ & $\begin{array}{l}31,14^{\text {A a }} \\
(2,50)\end{array}$ & $\begin{array}{c}35,00^{\mathrm{B} \mathrm{a}} \\
(2,35)\end{array}$ & $\begin{array}{c}24,13^{\text {A a }} \\
(3,40)\end{array}$ & $\begin{array}{c}25,90^{\text {A a }} \\
(3,21)\end{array}$ \\
\hline
\end{tabular}

\footnotetext{
* Médias seguidas de mesma letra, maiúscula na coluna e minúscula na linha, não diferem estatisticamente pelo teste de Tukey ao nível de $95 \%$ de probabilidade considerando a mesma condição de umidade. Valores entre parênteses referem-se ao coeficiente de variação (\%) das amostras.
} 
distinta, ao passo que com a elevação do diâmetro das toras, os mesmos constataram redução significativa nos rendimentos em madeira serrada. Possivelmente, a distinção dos resultados obtidos entre esses trabalhos esteja relacionada, principalmente, ao número e a amplitude das classes diamétricas avaliadas, uma vez que o primeiro trabalho, em relação ao segundo, avaliou uma classe a mais e de maior amplitude. Além disso, os referidos trabalhos testaram modelos de desdobro distintos ente si.

Ainda, tanto para o rendimento bruto, quanto para o rendimento sem as rachaduras, em todos os modelos de desdobro, ao se comparar os resultados obtidos nas diferentes condições de umidade, verificou-se que a classe 2, após a secagem, apresentou uma maior redução do rendimento em comparação a classe 1 , sugerindo que a madeira proveniente das toras de menor diâmetro apresentou maior estabilidade dimensional em relação as toras de maior diâmetro. Nesse caso, conforme Calonego; Severo (2005), a maior estabilidade pode estar relacionada à composição da madeira, que no caso das toras de maior diâmetro costuma ser mais heterogênea, apresentando os lenhos juvenil e adulto, enquanto as toras de menor diâmetro são constituídas, normalmente, por um único tipo de lenho.

Vale destacar, os resultados do efeito do diâmetro sobre os rendimentos sem as rachaduras, pois apesar de, frequentemente, o diâmetro de toras ser associado a maior ou menor manifestação de rachaduras na madeira (LIMA; GARCIA, 2008), não se observou uma tendência quanto ao efeito dessa variável para a maior parte dos tratamentos avaliados. Lima et al. (2007) ao estudarem as rachaduras na madeira de Eucalyptus grandis, também não observaram o efeito do diâmetro na manifestação desse defeito.

Sobre o efeito do modelo de desdobro, foi possível observar diferença significativa em todas as condições investigadas, porém, com padrões diferenciados, dependendo do rendimento considerado.

Quando analisado o rendimento bruto nas duas condições de umidade, independentemente da classe diamétrica, as maiores médias foram obtidas pelos Modelos 1 e 2, com predominância do Modelo 1. Estes resultados estão relacionados ao número de cortes internos necessários para obtenção de tábuas, que foram maiores no Modelo 3 em relação aos demais avaliados, resultando na produção de uma maior quantidade de serragem. Além disso, no Modelo 3, diferentemente dos outros modelos, não houve reaproveitamento de costaneiras e as perdas por refilagem foram maiores.

Embora a eficiência operacional não tenha sido considerada neste estudo, verificou-se ainda que o Modelo 3, em comparação com os Modelos 1 e 2, indiferentemente do volume das toras processadas, envolveu um número maior de operadores, sendo necessário também um tempo maior para a produção das tábuas.

Quanto ao efeito do modelo de desdobro no rendimento em madeira serrada sem as rachaduras, dentro de cada classe, verificou-se diferença significativa nas duas condições de umidade avaliadas. Apesar de, inicialmente, não terem utilizado cortes simultâneos para a liberação das tensões internas de crescimento, as maiores médias foram obtidas pelos Modelos 2 e 3, com predominância do Modelo 3, principalmente para a classe 1. Enquanto as menores médias foram obtidas pelo Modelo 1, especialmente quando considerados os valores obtidos após o processo de secagem, decorrentes do aumento das rachaduras, que reduziram consideravelmente o rendimento em madeira serrada, e indicaram que a recomendação deste modelo de desdobro para o processamento de toras de Eucalyptus benthamii de baixo diâmetro deve ser realizada com cautela.

Comparando-se os rendimentos brutos com os rendimentos sem as rachaduras, verifica-se que esse defeito 
reduziu de forma considerável o aproveitamento da madeira, principalmente, quando considerados os resultados obtidos para os Modelos 1 e 2, que produziram tábuas de menor estabilidade dimensional do que aquelas produzidas no Modelo 3. Normalmente, por apresentar maior estabilidade, as tábuas radiais, em relação às tangenciais, também tendem a apresentar melhores resultados durante o processo de secagem, uma vez que retraem menos e consequentemente, apresentam rachaduras de menor intensidade.

Resultados similares, embora de forma menos pronunciada, também foram obtidos por Cunha et al. (2015) que ao estudarem o rendimento de Eucalyptus benthamii na condição saturada, comparando o rendimento bruto com o rendimento sem rachaduras, verificaram que este último foi em média 8,21 pontos percentuais inferior ao primeiro. Quando consideradas as médias obtidas no desdobro tangencial, a diferença foi maior, sendo de 10,82 pontos percentuais para a classe de 20 a $25 \mathrm{~cm}$ de diâmetro e de 10,65 pontos percentuais para a classe de 25,1 a $30 \mathrm{~cm}$ de diâmetro. Enquanto no desdobro radial, as diferenças observadas variam entre 5,70 e 5,67 pontos percentuais, respectivamente para as classes de menor e maior diâmetro.

Além disso, quando analisado isoladamente, verificou-se que para o rendimento sem rachaduras também houve uma grande variação dos valores entre as diferentes condições de umidade, novamente de forma mais pronunciada nos Modelos 1 e 2, e observou-se uma drástica redução dos rendimentos após a secagem natural, evidenciando que os efeitos das tensões de secagem também contribuíram para o aumento das rachaduras longitudinais das tábuas.

Quanto ao potencial de utilização do Eucalyptus benthamii como fonte de matéria prima para serrarias, quando considerado o rendimento em madeira serrada, observou-se que os resultados obtidos para o rendimento bruto, tanto na condição saturada (35,33 a 43,44\%), como na condição seca (29,55 a 34,19\%), aproximaram-se dos resultados obtidos para outras espécies do mesmo gênero. Anjos; Fonte (2017b), ao estudarem o rendimento bruto, após o desdobro, de três espécies de Eucalyptus, incluindo o Eucalyptus saligna e o Eucalyptus grandis, espécies tradicionalmente empregadas na produção de serrados, observaram valores variando entre 36,71 e $53,55 \%$. Já Del Menezzi et al. (2001), ao avaliarem o rendimento bruto de madeira serrada, após a secagem, verificaram rendimentos entre $31,7 \%$, para o Eucalyptus grandis, e 39,3\% para o Eucalyptus cloeziana.

No entanto, quando considerados os resultados obtidos para os rendimentos sem as rachaduras, na condição saturada (24,55 a 37,82\%), verifica-se que estes são inferiores aos valores obtidos por Cunha et al. (2015), que para o Eucalyptus benthamii, logo após o desdobro, observaram rendimentos sem rachaduras entre 41,35 e 51,55\%. Contudo, quando ponderados os resultados obtidos para o rendimento sem as rachaduras, na condição seca (13,21 a 25,90\%), pôde-se verificar que estes se aproximaram dos valores obtidos por Amparado et al. (2008), que para o Eucalyptus saligna, utilizando toras de baixo diâmetro e descartando os topos das tábuas contendo rachaduras, empenamentos severos e nós soltos, verificaram após a secagem um rendimento em madeira serrada livre de defeitos de $24 \%$.

Mesmo assim, os rendimentos obtidos neste estudo estão abaixo do esperado pelo gênero Eucalyptus, que segundo Blackwell e Walker (2006), variam entre 40 e $65 \%$, o que possivelmente está relacionado às idades dos materiais avaliados, provenientes de árvores jovens, que, provavelmente, produziram toras de conicidade acentuada e menor estabilidade dimensional.

\section{Conclusões}

O rendimento bruto em madeira serrada foi maior nos Modelos 1 (em bloco) e 2 (em bloco com uma face curva) e 
apresentou tendência de elevação com o incremento da classe diamétrica.

O rendimento sem rachaduras em madeira serrada foi pouco influenciado pela classe diamétrica. Os maiores rendimentos foram obtidos no Modelo 3 (radial) e os piores no Modelo 1 (em bloco), indicando que o seu emprego no processamento de toras de Eucalyptus benthamii, com os diâmetros aqui avaliados, não é recomendado.

No geral, o rendimento bruto em madeira serrada de Eucalyptus benthamii, verificados nas diferentes condições de umidade, aproximam-se dos resultados encontrados na literatura para outras espécies de Eucalyptus. Já o rendimento sem as rachaduras é inferior ao encontrado por outros autores ao estudarem o mesmo gênero, especialmente, após o processo de secagem, e indicam, que na idade estudada, o Eucalyptus benthamii apresentou baixa viabiliadade para a utilização como matéria-prima para serrarias.

\section{Referências}

AMPARADO, K. F.; CARVALHO, A. M.; GARCIA, R. A.; LATORRACA, J. V. F. Caracterização do rendimento em madeira serrada de Eucalyptus saligna Smith nas condições verde e seca. Revista Florestal Venezolana, ano XLII, v. 52, p. 71 76, 2008.

ANJOS, R. A. M.; FONTE, A. P. N. Comparação da qualidade da madeira serrada de três espécies de Eucalyptus. Ambiência, v. 13, n. 1, p. 151 - 165, 2017a.

ANJOS, R. A. M.; FONTE, A. P. Rendimento em madeira serrada de espécies de Eucalyptus. Revista de Ciências Agroveterinárias, v. 16, n. 1, p. 26 - 32, 2017 b.

BIECHELE, T.; NUTTO, L.; BECKER, G. Growth strain in Eucalyptus nitens at different stages of development. Silva Fennica, v. 43, n. 4, p. $669-679,2009$.

BLACKWELL, P.; WALKER, J. C. F. L. Sawmilling. In. WALKER, J. C. F (Org). Primary wood processing: principles and practice. $2_{\text {a. }}$ ed. Berlin: Springer, 2006. p. 203-250.
CADEMARTORI, P. H. G.; GATTO, D. A.; STANGERLIN, D. M.; MASTELLA, T.; VARGAS, J. F. V.; SANTINI, E. J. Uso de herbicida na redução das tensões de crescimento na madeira serrada de Eucalyptus grandis. Ciência Florestal, v. 25, n. 3, p. $801-808,2015$.

CALONEGO, F. W.; SEVERO, E. T. D. Efeito do diâmetro de toras na magnitude das tensões de crescimento de Eucalyptus grandis. Energia na Agricultura, v. 20, n. 2, p. 53-65, 2005.

CARVALHO, A.M.; GONÇALVES, M. P. M.; AMPARADO, K. F.; LATORRACA, J. V. F.; GARCIA, R. A. G. Correlações da altura e diâmetro com tensões de crescimento em árvores de Corymbia citriodora e Eucalyptus urophylla. Árvore, v. 34, n. 2 , p. $323-331,2010$.

CUNHA, A. B.; FRANÇA, M. C.; ALMEIDA, C. C. F.; GORSKI, L. G.; CRUZ, R. C.; SANTOS, D. Avaliação do rendimento em madeira serrada de Eucalyptus benthamii e de Eucalyptus grandis por meio do desdobro tangencial e radial. Floresta, v. 45, n. 2, p. 241-250, 2015.

DEL MENEZZI, C. H. S.; NAHUZ, M. A. R. Comportamento de Eucalyptus grandis no desdobro. Árvore, v. 22, n. 4, p. 563 - 571, 1998.

DEL MENEZZI, C. H. S.; NAHUZ, M. A. R.; SOUZA, M. R. Utilização de um método combinado de desdobro e secagem para a obtenção de madeira serrada de eucalipto destinada à produção de painéis colados lateralmente. Árvore, v. 25, n. 1, p. 113-123, 2001.

ELEOTÉRIO, J. R.; HORNBURG, K. F.; REICHERT, D.; BAGATTOLI, T. R.; MENEGHELLI, I. Efeito da espécie e da condição de secagem na formação de defeitos na madeira serrada de eucalipto. Scientia Forestalis, v. 42, n. 101, p. 41 - 47, 2014.

GRAÇA, M. E. C.; SHIMIZU, J. Y.; TAVARES, F. R. Capacidade de rebrota e enraizamento de Eucalyptus benthamii. Boletim de Pesquisa Florestal, n. 39, p. 135 - 138, 1999.

JONES, T. G.; MCCONNOCHIE, R. M.; SHELBOURNE, T.; LOW, C. B. Sawing and grade recovery of 25-year-old Eucalyptus fastigata, E. globoidea, E. muelleriana and E. pilularis. New Zealand Journal of Forestry Science, v. 40, p. 19 - 31, 2010 
JUIZO, C. G. F.; ROCHA, M. P.; BILA, N. F. B. Avaliação do rendimento em madeira serrada de eucalipto para dois modelos de desdobro numa serraria portátil. Floresta e Ambiente, v. 21, n, 4, p. 543 - 550, 2014.

KOJIMA, M.; YAMAJI, F. M.; YAMAMOTO, H.; YOSHIDA, M.; NAKAI, T. Effects of the lateral growth rate on wood quality parameters of Eucalyptus grandis from different latitudes in Brazil and Argentina. Forest Ecology and Management, v. 257, n. 10, p. 2175 - 2181, 2009.

KOJIMA, M.; YAMAMOTO, H.; SAEGUSA, K.; YAMAJI, F. M.; YOSHIDA, M.; YAMASHITA, S.; NAKAI, T. Anatomical and chemical factors affecting tensile growth stress in Eucalyptus grandis plantations at different latitudes in Brazil. Canadian Journal of Forest Research, v. 42, n. 1, p. $134-140$, 2012.

LIMA, I. L.; GARCIA, J. N.; STAPE, J. L. Influência do desbaste e da fertilização no deslocamento da medula e rachaduras de extremidade de tora de Eucalyptus grandis Hill ex-Maiden. Cerne, v. 13, n. 2, p. 170 - 177, 2007.

LIMA, I. L.; GARCIA, J. N. Influência do desbaste e da fertilização nos índices de rachamento após o desdobro e secagem em madeira serrada de Eucalyptus grandis Hill ex-Maiden. Revista do Instituto Florestal, v. 20, n. 2, p. 175 - 184, 2008.

ROCHA, M. P.; TOMASELLI, I. Efeitos do modelo de corte nas dimensões de madeira serrada Eucalyptus grandis e Eucalyptus dunnii. Floresta e Ambiente, v. 8, n. 1, p. 94 - 103, 2001.

ROCHA, M. P.; TOMASELLI, I. Efeito do modelo de desdobro na qualidade da madeira serrada de Eucalyptus grandis e Eucalyptus dunnii. Cerne, v. 8, n. 2, p. 70 - 83, 2002.

ROCHA, M. P.; TRUGILHO, P. F. Qualidade da madeira serrada de Eucalyptus dunnii em função do método de desdobro e condição de umidade. Cerne, v. 12, n. 4, p. 314 - 321, 2006.

SILVA, J. C.; CARVAlHO, A. M. M. L.; FARIA, B. F. H. Methods for alleviation and reduction of the effects of growth stresses in Eucalyptus urophylla. Árvore, v. 41, n. 4, p. [S.I.], 2017.

SOARES, C. P. B.; PAULA NETO, F.; SOUZA, A. L. Dendrometria e inventário florestal. Viçosa: Ed. UFV, 2006.

SOUZA, J. T.; TREVISAN, R.; DENARDI, L.; STANGERLIN, D. M.; VIVIAN, M. A.; HASELEIN, C. R.; SANTINI, E. J.
Qualidade da Madeira serrada proveniente de árvores dominantes e médias de Eucalyptus grandis submetidas à secagem. Cerne, v. 18, n. 1, p. 167-174, 2012.

WADE, M. W.; BULLARD, S. H.; STEELE, P. H.; ARAMAN, P. A. Estimating hardwood sawmill conversion efficiency based on sawing machine and log characteristics. Forest Products Journal, v. 42, n. 11/12, p. 21 - 26, 1992.

WASHUSEN, R.; HARWOOD, C.; MORROW, A.; NORTHWAY, R.; VALENCIA, J. C.; 4, VOLKER, P.; WOOD, M.; FARRELL, R. Pruned plantation-grown Eucalyptus nitens: effect of thinning and conventional processing practices on sawn board quality and recovery. New Zealand Journal of Forestry Science, v. 39, p. 39 - 55, 2009. 